Article

\title{
The Role of Popular Culture for Queer Teen Identities' Formation in Netflix's Sex Education
}

\author{
Lucía-Gloria Vázquez-Rodríguez *, Francisco-José García-Ramos and Francisco A. Zurian \\ Department of Applied Communication Sciences, Complutense University of Madrid, Spain; \\ E-Mails: luciaglv@ucm.es (L.-G.V.-R.), fjgarciaramos@ucm.es (F.-J.G.-R.), azurian@ucm.es (F.A.Z.) \\ * Corresponding author
}

Submitted: 30 January 2021 | Accepted: 12 April 2021 | Published: 13 September 2021

\begin{abstract}
Queer teenagers are avid readers of popular culture; as numerous audience studies prove, television plays a significant role in identity-formation for LGBTIQ+ youth, providing them with the information about sexuality, gender roles or non-normative relationships usually unavailable in their educational and home environments. In this article we analyze how some of the protagonists of Netflix's TV show Sex Education (2019-present) utilize popular culture as a tool to explore their desires, forbidden fantasies, and gender expressions, becoming instrumental in the formation of their queer identities in a way that metatextually reflects the role LGBTIQ+ shows play for their audiences. Such is the case of Adam, a bisexual teenager that masturbates to the image of a fictional actor featured in a 1980s action film poster; Lily, whose sexual fantasies of role playing with alien creatures are strongly influenced by spatial sci-fi; and Ola, whose onyric universe is influenced by David Bowie's genderbending aesthetics. However, the most representative example of how popular culture influences the formation of queer identities is Eric, whose non-conforming gender expression follows the example set by the trans characters in Hedwig and the Angry Inch.
\end{abstract}

\section{Keywords}

gender identity; identity formation; LGBTIQ+ media; popular culture; queer; Sex Education; teens

\section{Issue}

This article is part of the issue "From Sony's Walkman to RuPaul's Drag Race: A Landscape of Contemporary Popular Culture" edited by Tonny Krijnen (Erasmus University Rotterdam, The Netherlands), Frederik Dhaenens (Ghent University, Belgium) and Niall Brennan (Fairfield University, USA).

(C) 2021 by the authors; licensee Cogitatio (Lisbon, Portugal). This article is licensed under a Creative Commons Attribution 4.0 International License (CC BY).

\section{Introduction}

In this article we analyze the role popular culture plays for the exploration of non-normative desires, forbidden fantasies, and non-conforming gender expressions amongst the teen protagonists of Netflix's TV show Sex Education (2019-present). Specifically, we focus on the ways in which a wide range of cultural products impact on the intersectional identity-formation (Crenshaw, 1989) and self-acceptance of those characters who could most accurately be defined as queer (Vázquez-Rodríguez et al., 2020). Regarding the meaning of the word queerness, we not only follow Sedgwick's (1990) and Butler's (1991) notions of gender performativ- ity and fluidity, but also understand the concept as referring to any form of otherness that challenges the hegemonic norm, going a step beyond the simplifying notion that equates queerness with non-cisheterosexuality. This theoretical framework allows us to consider instances and characters that do not necessarily fit the identity labels comprised by the LGBTIQ+ acronym, capturing instead a fluid and shifting understanding of the self that rejects rigid, essentialist, and static structures of identity, and turning our attention to characters that define themselves in opposition to the normal rather than the straight (Warner, 1993). In addition, we believe that the protagonists' identities and the places they occupy in the social hierarchy are not only determined by their gender 
expression and/or sexual orientation, but also by other vectors of oppression such as race, class, or disability that, as Crenshaw (1989, p. 139) explains, should not be treated as "mutually exclusive categories of experience and analysis," because the dynamics between coexisting identities (e.g., homosexual and black) and connected systems of oppression (e.g., heteropatriarchy and white supremacy) are inherently interconnected.

It is worth noting that the examples of mainstream shows that include sexually diverse characters in their plots have multiplied exponentially in the past decade; as Wendy Peters (2016) reveals, between June 2010 and June 2011, teenage TV fiction included more non-heterosexual characters than in the previous two decades combined. Other examples of this trend are The Chilling Adventures of Sabrina (Netflix, 2018-present), Euphoria (HBO, 2019-present) or Elite (Netflix, 2017-present), demonstrating that video-ondemand platforms offer great sources of representation of teen LGBTIQ+ realities. Despite the aforementioned increase in queer characters on widespread teen shows, the field of adolescent studies is still relatively minor within general (queer) media scholarship. There is a wide range of books and academic articles exploring either queer television (see for example Chambers, 2009, or Davis \& Needham, 2008) or TV shows for teenagers (e.g., Davis \& Dickinson, 2004), but not so much scholarship specifically focused on TV shows targeted at queer teenagers apart from individual chapters included in the aforementioned edited collections. Notable exceptions to this trend are Christopher Pullen's Queer Youth and Media Cultures (2014), and-although the focus is not specifically on TV but on general popular culture-Susan Driver's 2008's anthology entitled Queer Youth Cultures. Considering not only the increasing visibility of queer teen characters in TV fiction but also the multiplication of non-normative identities, sexual orientations, and gender expressions that go beyond categorial identity markers such as "lesbian" or "gay," the continued lack of focus on adolescent characters and audiences somehow comes as a surprise. In this sense, we agree with Meyer's assertion that "our scholarly attention must focus on representation in adolescent texts as much as those in adult oriented texts" (2003, p. 271).

As Laury Nunn-creator and screenwriter of the series-explains: "Audiences are looking to see themselves reflected in the characters, as well as watch content from different perspectives, so inclusive storytelling is really important to our show" (Phillipson, 2019). Although as several authors point out (e.g., Pullen, 2014), the increasing visibility of LGBTIQ+ people in popular culture (particularly within video-on-demand platforms) may respond to commercial interests (the multiplication of LGBTIQ+ and teen audiences, for instance) rather than reflecting an actual change in the values of the status quo. Nevertheless, the inclusion of LGBTIQ+ representativity as a selling value across all genres and cultural forms also means that queer teenagers will have more opportuni- ties to develop their identities utilizing a wider range of images as role models.

The show follows the adventures of Otis Milburn (Asa Butterfield) in his high school, located in a rural setting in the outskirts of Cardiff (Wales). Having observed his mother, a sex therapist, he establishes a sex counselling service for his peers with the help of his classmate and love interest Maeve (Emma Mackey). Each episode focuses on an issue related to adolescent sexuality, depicting numerous gender identities and sexual orientations. However, some of the clichés related to teen television persist in the series, such as the idea that adolescents are in a period of transition, do not yet have a defined identity, and are particularly vulnerable to peer pressure, all factors that render these characters more easily influenced by popular culture in their identity-formation processes. Indeed, as numerous audience studies prove (e.g., Meyer \& Wood, 2013) television plays a significant role in identity-formation for LGBTIQ+ youth, providing them with the information about sexuality, gender roles, or non-normative relationships usually unavailable to them in their (mostly) heteronormative educational and family environments. Given that popular culture constitutes a privileged apparatus for the socialization of gender and sexuality among its young audience, this type of production, along with the various cultural products allow us to observe the reconfigurations of power relations in terms of the diverse expressions of gender and sexual orientations presented by their protagonists.

It is important to note that not all examples of cultural products mobilized by LGBTIQ+ people-and by the show's protagonists-as a source of inspiration for the formation of their gendered identities or sexual orientations have been produced with a queer lens. At a time where there were no possibilities for the development of openly queer popular culture, LGBTIQ+ people proved the unlimited potential of the queer imagination and world-making processes (Muñoz, 1999) by decoding a wide variety of texts against the mainstream, heterosexual grain (Hall, 1973). Since heteronormativity is the hegemonic discourse spread from all cultural industries - specifically television, a medium traditionally associated with family and the domestic -in most cultural products produced before the new millennium, people who did not fit into the binary, heteronormative matrix remained in the blind spot. This meant that we had to develop queer reading practices in order to negotiate our identity needs and build non-normative role models. As Lipton explains, "Queer reading practices articulate queer positions in and about mass culture that reveal popular culture need not exclusively and inevitably express straightness" (2008, p. 104). In other words, cultural products constitute open, unfinished texts whose meaning is woven between the authors and the readers, who decode them by bringing their specific socio-political backgrounds, individual fantasies, and intersectional identities, questioning the various modes 
by which desire and identity are produced. Therefore, when queer subjects-particularly teenagers-actively engage with popular culture, the negotiated meanings they make of films, graphic novels, or songs "reveal a great deal about the queer imagination and its relationships to sexual desire and political resistance" (Lipton, 2008, p. 164).

In light of the above, we aim to determine how popular culture shapes the non-normative desires and fantasies of some of the characters featured in Sex Education's first two seasons. Based on previous analyses of the identity, desires, and behaviours of all the show's teen protagonists (Vázquez-Rodríguez et al., 2020), we will take as a case study four of the most clearly queer characters who, at the same time, present remarkable narrative and dramatic relevance: Eric Effiong (Ncuti Gatwa), Adam Groff (Connor Swindell), Ola Nyman (Patricia Allison), and Lily Iglehart (Tanya Reynolds).

\section{Methodology}

To study the role of popular culture on the identityformation of the queer characters in Sex Education we have employed a qualitative methodology anchored in textual analysis that incorporates a queer theoretical perspective and takes into account iconographic approaches to media texts. Following Evans and Gamman (1995), we believe there is a common cultural imagery that queer subjects put into play on the decoding (Hall, 1973) and reappropriation of popular culture. As such, we follow Muñoz's (1999) conceptualization of "disidentifications" as the survival strategies integrated by queer subjects (particularly queer subjects of color) in order to subsume dominant artistic expressions for the purposes of creating their own unique expression and conforming their identities within a cultural sphere that often elides the existence of those who do not conform to normative citizenship. This cultural imagery, whether openly non-normative or just open to queer readings is undeniably incorporated in the protagonists' articulation of their own sexual and gender identities. Here, we employ the term "queer teens" as a category of analysis to refer to young people whose identities "exceed the boundaries of straight gender and/or sexual categories" (Driver, 2008, p. 2). Far from imposing a new label, the term encompasses those who define themselves as gay, lesbian, bisexual, trans, intersex, queer, pansexual, and/or non-binary, expanding the definition to also include those teenagers whose fantasies defy the norm. Our research builds upon a long-established tradition that frames queerness as a mobile articulation of the desires, identities, and activities of sexual and gender minorities stemming from their interactions with popular culture, subcultural communities, and political movements. Following Rasmussen et al. (2016), we understand queer adolescents as essentially agentic subjects that draw on different references in order to define and imagine themselves, eschewing the prevailing approach that frames them as infantile victims passively affected by normative ideals they are unable to negotiate.

Evidently, when discussing the sexual identityformation processes of Sex Education, our approach is strongly anchored in a social constructionist, environmentalist paradigm that forecloses essentialist views on LGBTIQ+ subjectivities (Eliason \& Schope, 2007). There are several ideas frequently repeated amongst the theoretical models proposed to understand sexual identityformation for which the role of popular culture-and its articulation in the show object of study-is particularly clear. Eliason and Schope (2007, p. 13) signal the feeling of differentness as crucial for the development of non-normative sexual identities, expressed through the differential cultural preferences of the characters.

Adopting a cultural studies' perspective which considers popular culture a site that both embraces and resists hegemonic culture, we have selected those scenes in seasons 1 and 2 of the show featuring significant instances that provide insightful examples of the way popular culture is mobilized as a tool for nonnormative identity-formation processes. Hence, we will use as analytical categories the role diegetic music, films, fashion, graphic novels, and the internet play in the development of repressed desires and/or nonconforming gender expressions for those queer characters that incorporate particular references from popular culture in their daily life, tastes, or fantasies, and whose narrative and dramatic relevance merits a more thorough examination. Therefore, some of the cultural references we will be analyzing throughout the article are not only pivotal for the development of individual desires and alternative gender expressions, but also constitute essential signifiers of the changes occurring in the relationships among queer characters.

As such, the themes we have chosen to analyze in this article can be summarized in the following statements: 1) key popular texts, whether openly queer or not are integrated in the development of the non-normative fantasies and desires deployed by the character's object of study; 2) popular culture references are narratively and aesthetically incorporated by some of the show's protagonists in order to build their non-conforming gender expressions; 3 ) cultural texts have a significant role for the development of queer relationships amongst the characters analyzed.

\section{Popular Culture's Key Role for Sex Education's Queer Protagonists}

\subsection{Eric Effiong}

Eric constitutes one of the queerest characters included in the show whose identity is determined by diverse intersecting vectors of oppression that simultaneously reproduce particular places of oppression and exclusion. $\mathrm{He}$ is religious, presents a non-normative gender expression, is black and coming from a working-class family, 
and, despite being Otis' best friend, in no moment is he relegated to the superficial role of "gay best friend." His self-consciously exaggerated clothing and makeup seamlessly fit within the camp aesthetic paradigm defined by Sontag (1964), which Dyer (2002) later identified as a form of queer resistance. Following Luu (2018), we identify campness as a form of theatrical self-expression that subverts the gender binaries that fail to contain Eric's identity, something particularly visible in the drag he and Otis do every year for his birthday, dressing up as Hedwig (see Figure 1), from queer cult musical film Hedwig and the Angry Inch (Mitchell, 2001).

The choice of Hedwig as a role model for the development of Eric's non-conforming gender identity is a particularly interesting example of the ways popular culture is integrated and re-interpreted by Sex Education's queer protagonists. Although the show does not provide a label for Eric's gender identity-he does, however, repeatedly describe himself as gay-his character can be most accurately described as gender-y, in the sense outlined by Sedgwick (1990). "Gendery" - or non-binaryrefers to the quantity rather than the quality of gender signifiers, permitting the coexistence of multiple gender axes-such as butch-femme, masculine-feminineand breaking down the conventional gender dichotomy between masculinity and femininity. Although he enjoys some of the aspects related to the performance of femininity (Butler, 1991), such as putting makeup on, dressing up in drag, or wearing African women's headpieces, Eric also integrates in his identity several behavioral and visual signifiers that mark him as "a man" (on E6S1, for example, he punches Anwar in the face, displaying a form of aggression generally associated with hege- monic masculinity). Much like Hedwig, who alternates between more femme and more masculine appearance, Eric switches from one to the other with ease, particularly in his outfits. However, his return to a more conventionally masculine performance after the trans homophobic aggression he suffers (E5S1) is narratively read as a form of surrender to socially acceptable gender norms to grant him physical safety rather than interpreted as a sign of gender play. The morning after being physically abused for dressing up as Hedwig he puts on bland, beige clothes designed to mask himself as conventionally masculine. In this episode, he is effectively dressing up as a cisheterosexual man, doing straight drag in a manner that renders his male performance more unnatural than his female drag ever was.

In this sense, since Eric is not a trans character, his most recognizable role model could not be a conventional trans person either. Refusing the widespread approach to transsexuality that frames sex change as the only way to create a sexed body coherent with the protagonist's gender identity, Hedwig and the Angry Inch tells a story of an individual that utilizes sex change to escape East Berlin rather than due to her own desire to transition. Indeed, her sex change operation goes wrong, leaving her with the angry inch that lends its name to the film instead of endowing her with the genitals that would render her physically readable as a "woman." Both Hedwig's and Eric's refusal or inability to define their gender identity in essentialist/absolute terms constitute an undeniably queer gesture. John Cameron Mitchell did not conceive his film as a way to advance transgender politics just as Laurie Nunn did not intend for Eric to become a teenage trans symbol, constructing in turn

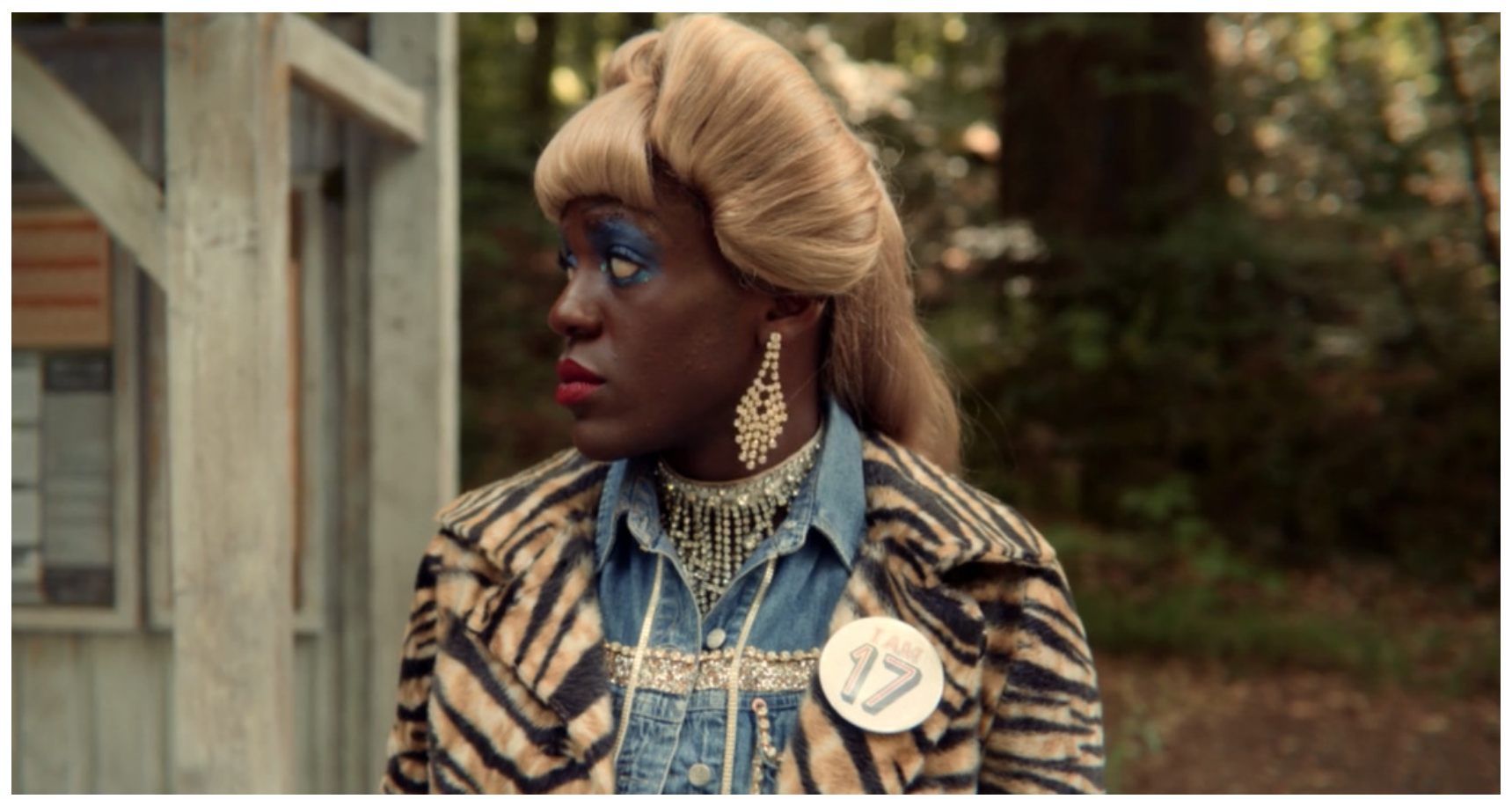

Figure 1. Eric dressed up as Hedwig (E7S1). 
characters that can be utilized to challenge the reification and naturalization of normative binaries. Much like Gatwa's character is, for his queer fans, a flamboyant celebration of sexual freedom especially signified by his iconic camp outfits, Hedwig's has become his own inspiration, while traces of David Bowie can be found in the latter's gender expression. Hedwig also wears a Farrah Fawcett wig (also worn by Eric on his birthday) and emulates Tina Turner on her music performances (Hsu, 2007, p. 108); specific female celebrities (Madonna, Cher, Dolly Parton, etc.) have always been prominent role models for the gay/drag/trans community. Significantly, the first time we see Eric applying make-up and therefore performing his queer/drag identity he is listening to Tina Turner's cover of Anne Peebbles' classic / Can't Stand the Rain in what could be understood as an intergenerational form of cultural reappropriation; here, a song performed by a white, heterosexual woman is being utilized as a means for the (gender) self-expression of a queer character of color, who not only listens to her but also utilizes the female icon's fashion style as a source of inspiration. Therefore, his animal print garments (which could be accurately defined as camp) emulate Tina Turner's typical leopard skin outfits (she was known as "the panther"), such as the one she wears for the videoclip of Love Thing.

Additionally, in E3S1, Lily finds out that Eric owns women's clothes, but when she confronts him about it, he responds that he is "not a ladyboy or anything," refusing to identify as other than a man who likes to dress up. Then, they play with makeup, creating a look for Eric that is undoubtedly inspired by the Black trans characters from queer cult film Paris is Burning (Jennie Livingston, 1990; see Figure 2). Produced in 1990, this was a key documentary film for the visibilization of queer people of color, creating recognizable role models for gender non-conforming black teenagers such as Eric himself that were largely absent from popular culture before. Furthermore, Eric goes to the school dance sporting glitter makeup, a Ghanian-inspired headpiece, Africanmade earrings, vinyl high heel shoes, and a kente suit, in what constitutes an homage to both his African heritage and to Brooklyn's iconic ballroom drag scene, represented in Paris is Burning. His Nigerian-influenced glam drag, "explicitly if briefly makes visible the black origins of so much queer music and performance" (Mayer, 2020, p. 37), perhaps constituting the most open reference to objects from black queer culture present in the show.

Therefore, drag plays a significant role for both Hedwig and Eric's identities; in its parodic imitation of femininity, it becomes a way to "implicitly reveal the imitative structure of gender itself-as well as its contingency" (Butler, 1991, p. 175). Their gender play does not revolve around "imitating" an original or natural form of femininity. Although Hedwig provides her audiences with a much more radical example of queer politics than Eric, both their gender performances nonetheless embody Queer Theory's notions of parody, performativity, and the impossibility of relying upon the sex/gender system as a marker of identity. The show's perhaps self-conscious choice to avoid politicizing Eric's identity and delve less deeply into his gender expression, not providing him with a label may be read as a way to avoid alienating an audience that is conceived as relatively niche, but not as much as Hedwig's. Partly due to their widely diverging channels of distribution, Sex Education could not endow Eric with as liminal a status as Hedwig enjoys.

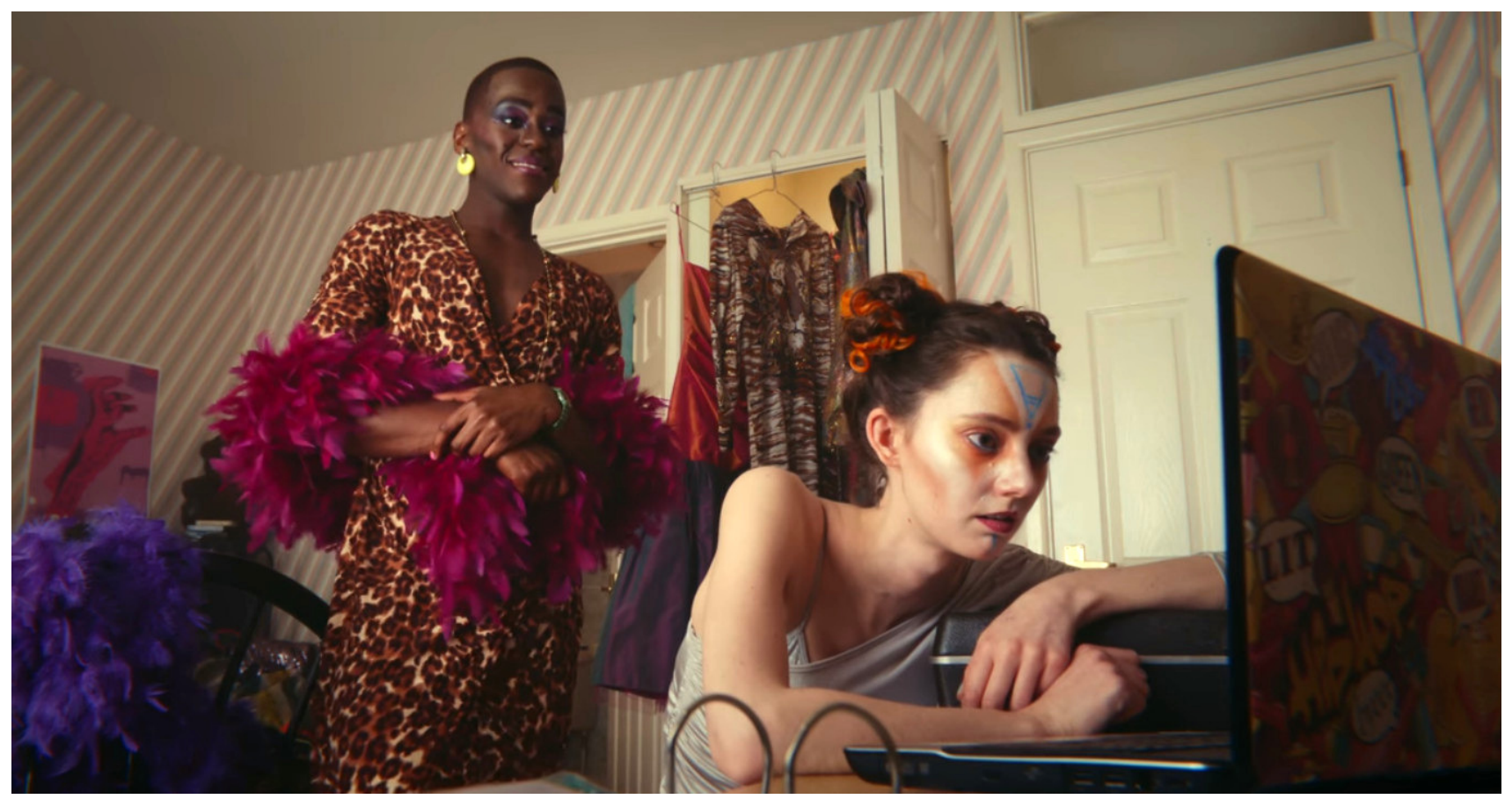

Figure 2. Eric and Lily on drag (E5S1). 
Hedwig finds in Glam Rock a space for the development of fluid gender expressions, finding inspiration in queer idols such as David Bowie's gender-bending Ziggy Stardust incarnation, Freddie Mercury, or Prince (Hsu, 2007, p. 104). As John Cameron Mitchell explains "the rock and the drag were all mixed up already," citing androgyny as quintessential for rock (as cited in Eliscu, 2001, p. 29). While Eric does not play in a punk band, he does play the French horn in his school's Swing Bang and displays a love for musical theatre generally associated with queer masculinities. Although his defiance to the heteronormative (and even to the homonormative) is most accurately depicted through his outfits, diegetic music still plays a key role for his self-acceptance as a gay, potentially gender-fluid individual. Disco and funky songs, which constitute a gay-male signifier based on its historical existence as a dance subculture dominated by gay men in US cities (Dyer, 1979) are often playing in the background at key moments where Eric performs his queer identity, privately and in front of others. For example, Eric campily dances and twerks to We Got the Funk (Positive Force)-a song that gave name to Oakland's 2010 LGBTIQ+ Pride Festival-when he tries to persuade Otis to go to a party in E3S2. Additionally, when he teaches Ruby how to perform fellatio utilizing a banana in that same party, it is the song Take on Me that is playing in the background; although A-ha's song is often categorized as "synth pop," its infectious, simple beats, and high notes trace a musical lineage that goes back to 1970s disco. According to Dyer (1979), disco music built a liberating space in the 1970s for queer men of color because of its "all-body eroticism," repetitive rhythms and "romanticism," allowing gay men to come together in non-homophobic, non-commercial spaces. While some authors consider that nowadays this space has been co-opted, white-washed and heterosexualized, it is nevertheless true that Eric integrates "the queer experience of disco" to negate a monolithic, phallic gay identity that does not fit his gender fluidity (Dyer, 1979, p. 159), constructing a subversive sensibility also inscribed in his fashion choices, that blend together disco aesthetics and African textiles. For Eric, music is used to contest gender and sexual norms, accommodating-particularly when he is dancing-emotional, physical, and sexual expressions perhaps unavailable to him in other aspects of his daily life (Taylor, 2012, p. 45).

In addition, diegetic music places a key role to mark the development of the queer relationships (whether romantic or not) depicted in the show: In S1's finale, Otis and Eric signify their reconciliation by dancing together to The Origin of Love (Hedwig's main theme) in front of their entire high school. The song's lyrics and animations featured in Mitchell's film refer to the Greek myth of humans divided into halves by the gods, condemned to search for another person to be complete, recounted by Plato in The Banquet (385-370 a.C.). Reinterpreting this platonic myth, Sex Education subverts the original heteronormative romantic-love narrative presenting instead two male friends, ultimately rejecting the message that Hedwig also negates: It is not love that will make us whole, but the establishment of (queer) communities. This relational dialectics expressed through music is clear in another instance (E4S2): For their first date, Eric takes Rahim to a fancy restaurant, a distinctly heteronormative place where they seem unable to express their attraction freely, so Eric takes him to an arcade, where they play a dancing videogame to the song What is Love? (Haddaway) immediately before kissing for the first time. Interpreted by a Black German singer of Triniadian ascent, the song's videoclip was originally presented as an interracial vampire story that alludes to an implicit connection between vampirism and a form of diseased, yet irresistible sexuality, a message only intelligible for those whose queer sexuality may also be seen as perverse. Musicals are so important for Eric that it is Rahim's dislike for them that ultimately marks their incompatibility (E8S2). Rahim's cultural references are very different from Eric's much more queer tastes; Rahim loves Pablo Neruda while Eric enjoys camp musicals. However, when Eric invites Adam to the school's play it is clear that, despite his more "macho" performance, he can enjoy musicals, asking if the show will be like Frozen, a film he watched despite deeming it sad, hinting at a mutual love for corny musicals as a queer sign of affective compatibility.

Although both Otis and Eric dress up as Hedwig, it is only the latter who is narratively punished for this gender transgression in E5S1. After having his belongings robbed and being stood up by Otis, two white men in a car laugh at Eric, to which he responds: "Please, this isn't me this is a costume" before he is immediately hit and spat on by one of them. On the other hand, Otis-being a white, more heteronormative character-is allowed to happily enlighten another white student on queer popular culture when he asks about his costume, which speaks of the intersectional nature of the oppression experienced by Gatwa's character (Crenshaw, 1989). Here, Johnson's (2005) "quare" framework (an African American vernacular of saying queer) can be integrated to explain the racialized, gendered, and class nature of Eric's material reality and the aggression he suffers: The fact that he is physically assaulted when being in drag while Otis is not forces the audience (even queer, white viewers) to be accountable to a raced body, rather than abstraction, disembodiment, and the devaluing of queers of color's fleshed experience (Johnson, 2005). Interestingly, although Eric could have picked a black queer symbol to emulate on his birthday he nevertheless chose Hedgwig, an extremely eurocentric role model from a musical, a genre generally associated with the queer, white upper classes, constituting a further example of Muñoz's disidentificatory performances (1999). This choice emphasizes the hegemony of American/European popular culture texts as opposed to more peripheral cultural references, even when those incorporating them to construct their identities and express them through artistic/creative performances do 
not come from a white, Western background. However, it is only after meeting a queer man of color on E6S1 that he goes back to his usual camp outfits, and the African prints he reinvents for his outfits-feminine turbans or kente suits-are a key marker of his queer identity.

\subsection{Lily Iglehart and Ola Nyman}

If we understand queerness as a rejection of normality in all its forms, Sex Education's most transgressive character would undoubtedly be Lily, an amateur comic book writer who, through her artistic expression has managed to create her own posthuman erotic universe. In her attempt not to be defined as the "weird virgin," Lily obsessively tries to lose her virginity with some of her classmates, disregarding their sex, gender, orientation, or corporality; she is even willing to pretend to be a boy in order to have sex with Eric (E3S1). However, rather than a human being, Lily's ideal sexual object is an alien. In this sense, Lily is presented as an androgynous being with futuristic outfits, galactic makeup, and a hairstyle reminiscent of antennae (see Figure 2); she utilizes prosthetic tentacles and recreates spatial scenarios in her room for her sexual encounters. The first time she has sex, she orchestrates a role playing scene based in her own artistic-literary imaginary universe, making out with a boy nicknamed "Octoboy" with whom she cannot culminate because her vagina contracts involuntarily, something Otis will later diagnose as vaginismus (E8S1).

The rich imaginary from which Lily articulates her identity and her sexual-affective relationships is manifested through her comic writing. Lily has created her own erotic-spatial universe full of sexual fantasies with strange alien creatures in a cyborg and post-human logic (Haraway, 1985) where the border between the animal, the human, and the alien is continuously transgressed. Far from marking the impossibility of coupling between subjects of different species, Lily poses a myriad of disturbing and pleasurable couplings through her literary proposals, her stage productions, and her own sexual performativity. Bestiality and inappropriate beings are initially represented by the giant octopus Kraken, who appears seductively showing his phallic tentacles embodied in "Octoboy" and in the plastic prostheses that Lily uses as a dildo. The Kraken, which in Scandinavian popular culture attacks ships and devours sailors, will be incorporated in contemporary popular culture after its appearance in the novel Twenty Thousand Leagues Under the Seas (Jules Verne, 1870) and featured in films such as Clash of the Titans (Desmond Davis, 1981), Pirates of the Caribbean: Dead Man's Chest (Verbinski, 2006) and several B horror films. However, it will be in the figure of the alien, which enables new forms of coupling and reproduction, where this affective-sexual twist that renders human heterosexual coupling meaningless culminates.

Lily's erotic universe is even translated to Ola's fantasies; in E5S2, she has a dream in which she kisses the latter, revealing her orientation as pansexual. Full of psychedelic lighting and electronic sounds, it reminds viewers of David Bowie's galactic videoclips, again borrowing aesthetic influences from one of the icons with the most ambiguous gender identities of all times. The song Early Rain-by punk rocker Ezra Furman-is playing in the dream; they were also responsible for curating and creating Sex Education's original soundtrack, conjuring "a movable feast where a queerer version of commonality and comfort" (Mayer, 2020, p. 37) allows the characters to come together in physical spaces and headspaces, bringing a level of genderqueerness to the show that is yet to be articulated at the narrative level (aside from Ola occasionally dressing like "a very small man," as her boss points out), thus linking a (transtemporal) musical education to a sexual one (Mayer, 2020, p. 37). Significantly, Furman identifies as bisexual and, inspired by Lou Reed, does not identify as man nor woman, "proud to exist in an ambiguous, undecided state" (Furman, 2015, para. 14). Music constitutes a resource for Ola and Lily's utopian queer world-making (Muñoz, 1999), strategically incorporated in their subconscious to presage new, alternative worlds in which they are not confined to dissatisfying straight relationships. Analyzing the music that Sex Education's queer protagonists listen to provides us with valuable insights into the way the construct their identities, for it is connected to gender, sex, and desire, and it has historically been utilized as a resource in queer identity-formation (Taylor, 2012, p. 142).

In this futuristic and transhuman eroticism not only Haraway's theoretical approach can be traced, but also the spatial fictions of feminist science fiction novels such as Anne McCaffrey's (e.g., The Ship Who Sang, 1969) or Joanna Russ' (e.g., The Female Man, 1975), as well as other graphic novels and films that explicitly appear in the series that Lily identifies with. For example, her explicit identification with Lieutenant Ripley from Alien: The Eighth Passenger (Ridley Scott, 1979) through her sexual cosplaying and her passion for Tank Girl (Alan Martin and Jamie Hewlett, 1988), which will lead in turn to her connection with Ola in season 2 . In this sense, Lily appears reading the comics several times and wears a badge featuring the iconic green tank, parallel to Ola's rainbow badge.

In truth, nothing about Lily corresponds to the idea we have of a British teenager who is white, well-to-do, cultured, intelligent, and with artistic sensibility. Her whole persona connotes strangeness, further exemplifying queerness' rallying cry against the regimes of the "normal" (Warner, 1993) through her musical adaptation of Shakespeare (which she writes and directs for the end-of-the-year performance). With it, Lily shares with her entire school her way of understanding sexuality by designing a phallic and vaginal staging that recreates her sci-fi fantasy universe in glam key (E8S2). Her adaptation is inspired, on the one hand, by the tradition of cult musicals for the queer community such as The Rocky Horror 
Picture Show (Jim Sharman, 1975); and, on the other, by recent queer re-readings of Shakespeare's plays, some of them performed at the Globe Theatre in London, such as Emma Rice's 2017 musical adaptation of Twelfth Night.

In this sense, Lily's musical adaptation of Romeo and Juliet is one of the queerest instances featured in the show, considering that normality, norm, or normativity are social constructs that privilege certain aesthetics, images, and lifestyles over others, and that transgressing them can be both artistically enlightening and sexually liberating. As Taylor explains, "music has been associated with sexual allure, gender inversion and suspect sexuality" in a manner that reflects the way both musicals and diegetic disco music act in the show as "an expressive mechanism of gender and sexual signification, capable of arousing and channelling sexual urges and desires" (2012, p. i).

\subsection{Adam Groff}

Adam is first introduced as a character while having sex with his high school girlfriend, with whom he cannot reach orgasm; he is presented in a passive, absent attitude. Moments later, Adam is shown as a troll (Zurian, 2013, p. 173), cornering Eric in his locker and stealing his money and food; he is perpetually framed as an outsider, not fully within the educational system despite being the dictatorial headmaster's son. His problematic relationship with his father, who always criticizes and belittles him, obviously inflicts serious harm to Adam's already bruised ego. The fact that he cannot culminate his sexual relations is further problematized by the widespread rumors that he has an "elephant dick," thus render- ing his phallus and sexual performance key issues for his identity.

In addition to his deep psychological issues, Adam is never placed in his own personal space. Contrarily, we see other characters in their private rooms (decorated according to their preferences, full of references to the popular culture that inspires them), as well as interacting with each other in public spaces. Adam wanders through space without fully occupying it, seemingly without an identity of his own beyond that of a bad student, a troll, and possessing a huge penis. Adam is full of silences, cold stares, and hatred towards himself and his father. However, we do not know the origin of this hatred until, in E8S1 he is sent to the school's detention room with Eric (whom he bullied for years), an encounter that ends with them kissing and Adam performing fellatio on Eric. Here, the screenwriters offer us a turning point that will begin to show part of the root of Adam's problems.

E5S2 shows Adam in the privacy of his room, at last. We see model airplanes hanging from the ceiling, a couple of nondescript paintings and the Ultimate Deadlock film poster (a made-up reference; see Figure 3). Inspired by 1980 s B-movie aesthetics, it features a muscular male protagonist (Tommy Tester) on the left and a sexy actress, Ava Speed-whose obvious to-be-lookedat-ness (Mulvey, 1975) reminds us of iconic figures like Ava Gardner and Sandra Bullock in the film Speed (Mark Mancini, 1994) - on the right, with a speeding car located between them. Adam looks lustfully at Tommy, running his gaze through his face and muscles while he masturbates, shaking his head in denial. He tries to look at the girl instead, but this immediately lowers his arousal, prompting him to return to the actor. Drawing

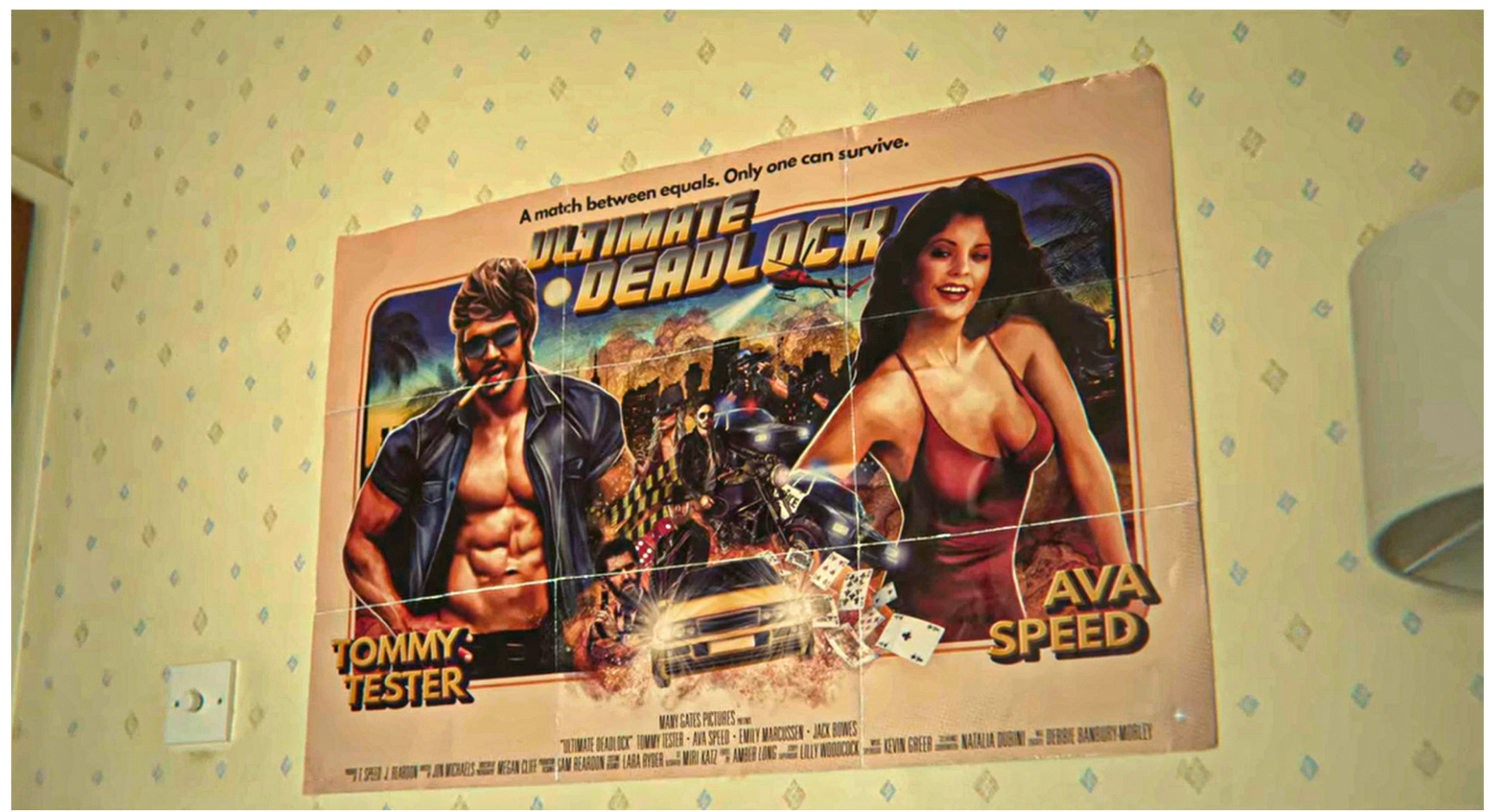

Figure 3. The Ultimate Deadlock poster (E5S2). 
on gay erotic myths deemed "not suspect" by straight audiences, Tester's appearance and costume are highly reminiscent of famous action actors such as Chuck Norris, Sylvester Stallone, and Arnold Schwarzenegger, whose powerful physique eternally on display constitutes a source of voyeuristic pleasure for queer male viewers, on a gay reversal of the Male Gaze (Mulvey, 1975) that Adam's commoditization of Tester's body further exemplifies. The position of the actor, utilized to emphasize his muscles, proves to the onlooker that he is an active subject (as opposed to passive, feminine men), "the end product of his own activity of muscle-building" (Dyer, 1982 , p. 62), portraying a form of masculinity highly common in popular culture that may not be read as too emasculating to young queer men coming to terms with their identities.

"A match between equals. Only one can survive"; the film's tagline summarizes Adams' conflict throughout his adolescence: the binary choice between homosexuality and heterosexuality, since bisexuality is initially not presented as a possibility. The poster represents a widespread social imagery in which there is no room to "match" both a man or a woman with fluidity, indistinctly; where bisexuality is only understood as a transitory phase, a "tester," or a disguise for unaccepted homosexuality. In this sense, the poster becomes a symbolic space (both visually and verbally) channeling Adam's identitary conflicts and internalized homophobia. Eventually, he will tell Eric, who becomes his love interest throughout S2 that he thinks he is bisexual, thus confirming his previously unacknowledged queer sexual orientation.

\section{Conclusions}

In the first two seasons of the show, cult films, pop songs, fashion trends, and graphic novels become instrumental in the formation of the main characters' queer identities in a way that metatextually reflects the role LGBTIQ+ audiovisual products play for those members of their audience whose sexual orientations and/or gender identities do not fit within the norm. As we have seen, popular culture becomes a source of inspiration and a site for the development of non-straight desires for Eric, whose non-binary gender expression follows the example set by the trans characters in Hedwig and the Angry Inch; Adam, a bisexual teenager whose sexual conflict is symbolized in the 1980s movie poster he masturbates to; and Lily, whose sexual fantasies of role playing with alien creatures are strongly influenced by Tank Girl, Lieutenant Ripley, and other spatial sci-fi. Perhaps due to the queer potential of the cultural objects incorporated in their identity-formation process, none of these characters adopt homonormative identities. Eric, Lily, Ola andto a lesser extent-Adam put into play a queer youth culture with sexual pleasures and cultural tastes that challenge the (hetero)normal; in this sense, they offer role models beyond the normalization of gay youth in popu- lar culture which, according to Driver "works to desexualize and depoliticize youth once again, creating safe, sanitized images that conform with white middle-class standards of visibility and value" (2008, p. 5).

By invoking famously queer musical and cinematic references crucial for identity-formation and for the establishment of queer genealogies amongst chosen families, Sex Education offers LGBTIQ+ teenagers a way to establish peer groups marked by their shared aesthetics, standing as a representational memorial "to an improvisatory, interstitial cultural moment" (Mayer, 2020, p. 38). TV representations of teenagers offer prescriptive identities to their target audiences, telling them how their gender and/or sexual identity should be built by incorporating the different values and references integrated by the protagonists of their favorite shows. This is even more true for teenagers, for whom these prescriptive modes of behavior and markers of taste will determine their belonging to any given group, a value crucial during adolescence (Zurian, 2013, p. 158). Popular culture thus remains one of the means by which queer adolescents both recognize and connect with others that share their experiences, desires, and struggles. By the perpetuation of shared popular culture references (sometimes reappropriated or negotiated by younger generations), "queer breeding provides a way for thinking about queer inheritances and proliferations that are not overdetermined by heteronormative logics of reproduction, hierarchy and binary" (Marshall, 2013, p. 603); for example, tracing a lineage of genderqueer popular culture icons that evolves from Bowie to Hedwig to Eric or even Ola. Therefore, Sex Education makes the history of queer popular culture visible, underlining the impact these references from books, films, and music have on the identity-formation and self-acceptance of queer teenagers (and TV characters) across different generations. The intertextual approach selected here is, in this sense, quite unique as it offers multiple insights on the different ways cultural texts are integrated by teen subjects as part of their nonnormative identity-formation processes. In other words, as Dhaenens explains, "the ongoing public debate about gay civil rights is not only waged in the political arena but also in popular culture" (2013, p. 304).

As we have proven, the creative queer potential of even cultural objects not positioned as overtly queer in form or content plays a significant role in the construction of the protagonists' queer fantasies and gender expressions, exemplifying the power of queer youth's imaginative re-readings. This is due to the fact that queer youth bring highly specific subcultural experiences and knowledge to the reading of popular texts that, to the general population, may be unknown or seem perfectly straight, such as Lily's highly queer musical interpretation of Romeo and Juliet or Adam's sexualized gaze upon a Sylvester Stallone fictional lookalike. Hence, all forms of popular culture are relevant for the identity-formation of the characters featured in Sex Education, although 
more ethnographic work should be conducted on how these representations may influence the development of non cisheteronormative subjectivities on the program's audiences. In a world where access to different media platforms is increasing rapidly, media scholars should devote more attention to exploring how adolescents utilize media and popular culture to form identity.

\section{Acknowledgments}

This article has been done within the framework of the Project "Memories of Dissident Masculinities in Spain and Latin America" (PID2019-106083GB-100) of the Spanish Ministry of Science and Innovation. The research has also been funded by the UCM-Santander Bank Predoctoral Contracts Program.

\section{Conflict of Interests}

The authors declare no conflict of interests.

\section{References}

Butler, J. (1991). Imitation and gender insubordination. In D. Fuss (Ed.), Inside/out: Lesbian theories, gay theories. Routledge.

Chambers, S. A. (2009). The queer politics of television. I. B. Tauris.

Crenshaw, K. (1989). Demarginalizing the intersection of race and sex: A black feminist critique of antidiscrimination doctrine, feminist theory and antiracist politics. University of Chicago Legal Forum, 140(1), 139-167.

Davis, G., \& Dickinson, K. (2004). Teen TV: Genre, consumption, and identity. BFI Publishing.

Davis, G., \& Needham, G. (2008). Queer TV: Theories, histories, politics. Routledge.

Dhaenens, F. (2013). Teenage queerness: Negotiating heteronormativity in the representation of gay teenagers in Glee. Journal of Youth Studies, 16(3), 304-317. https://doi.org/10.1080/13676261. 2012.718435

Driver, S. (2008). Queer youth cultures. SUNY Press.

Dyer, R. (1979). In defense of disco. Gay Left, 8, 20-23.

Dyer, R. (1982). Don't look now. Screen, 23(3/4), 61-73.

Dyer, R. (2002). It's being so camp as keeps us going. In R. Dyer (Ed.), The culture of queers (pp. 49-62). Routledge.

Eliason, M. J., \& Schope, R. (2007). Shifting sands or solid foundation? Lesbian, gay, bisexual, and transgender identity formation. In I. H. Meyer \& M. E. Northridge (Eds), The health of sexual minorities (pp. 3-26). Springer.

Eliscu, J. (2001, August 16). John Cameron Mitchell's walk on the wild side. Rolling Stone.

Evans, C., \& Gamman, L. (1995). The gaze revisited, or reviewing queer viewing. In P. Burston \& C. Richardson (Eds.), A queer romance: Lesbians, gay men and popular culture (pp. 13-56). Routledge.

Furman, E. (2015, July 3). Pretty punk rock: How Ezra Furman found freedom in gender fluidity. The Guardian. http://bit.ly/3tbKILu

Hall, S. (1973, September). Encoding and decoding in the televisual discourse [Paper presentation]. Colloquy on Training in the Critical Heading of Televisual Language, Birmingham, UK.

Haraway, D. (1985). A manifesto for cyborgs: Science, technology, and socialist feminism for the 1980s. Socialist Review, 15(2), 65-107.

Hsu, W. (2007). Reading and queering Plato in Hedwig and the Angry Inch. In T. Peele (Ed.), Queer popular culture (pp. 103-117). Palgrave Macmillan.

Johnson, E. P. (2005). Quare studies or (almost) everything I know about queer studies I learn from my grand-mother. In E. P. Johnson \& M. G. Henderson (Eds.), Black queer studies: A critical anthology (pp. 124-157). Duke University Press.

Lipton, M. (2008). Queer readings of popular culture. In S. Driver (Ed.), Queer youth culture (pp. 163-180). NYU Press.

Livingston, J. (Director). (1990). Paris is burning [film]. Miramax; Off White Productions; Prestige.

Luu, C. (2018, June 6). The unspeakable linguistics of camp. JSTOR Daily. http://bit.ly/3j90wtJ

Marshall, D. (2013). Queer breeding: Historicising popular culture, homosexuality and informal sex education. Sex Education, 13(5), 597-610. https://doi.org/ 10.1080/14681811.2013.811577

Mayer, S. (2020). Pan(dem)ic! At the Disco: Sex (and) education in Covid-19-era television. Film Quarterly, 74(1), 30-39.

Meyer, M. D., \& Wood, M. M (2013). Sexuality and teen television: Emerging adults respond to representations of queer identity on Glee. Sexuality \& Culture, 17(3), 434-448.

Meyer, M. D. (2003). It's me. I'm it: Defining adolescent sexual identity through relational dialectics in Dawson's creek. Communication Quarterly, 51(3), 262-276.

Mitchell, J. C. (Director). (2001). Hedwig and the angry inch [film]. New Line Cinema; Killer Films.

Mulvey, L. (1975). Visual pleasure and narrative cinema. Screen, 16(3), 6-18.

Muñoz, J. E. (1999). Disidentifications: Queers of color and the performance of politics. University of Minnesota Press.

Peters, W. (2016). Bullies and blackmail: Finding homophobia in the closet on Teen TV. Sexuality \& Culture, 20, 486-503. https://doi.org/10.1007/s12119016-9336-3

Phillipson, D. (2019, January 23). Sex Education is a triumph for LGBTQ+ representation. Digital Spy. https://bit.ly/2NLaJ3T

Pullen, C. (2014). Queer youth and media cultures. Palgrave Macmillan.

Rasmussen, M., Rofes, E., \& Talburt, S. (2016). Youth 
and sexualities: Pleasure, subversion, and insubordination in and out of schools. Springer.

Sedgwick, E. K. (1990). Epistemology of the closet. University of California Press.

Sontag, S. (1964). Notes on 'camp.' Partisan Review, 31(4), 515-530.

Taylor, J. (2012). Playing it queer: Popular music, identity and queer world-making. Peter Lang.

Vázquez-Rodríguez, L. G., García-Ramos, F. J., \& Hernández, F. A. Z. (2020). La representación de identidades queer adolescentes en 'Sex Education' (Netflix,
2019-) [The representation of queer teen identities in Sex Education (Netflix, 2019-)]. Fonseca, Journal of Communication, 21, 43-64.

Warner, M. (1993). Fear of a queer planet: Queer politics and social theory. University of Minnesota Press.

Zurian, F. A. (2013). Imagen, cuerpo y sexualidad: Representaciones del cuerpo en la cultura audiovisual contemporánea [Image, body and sexuality: Representations of the boy in contemporary audiovisual culture]. Ocho y Medio.

\section{About the Authors}

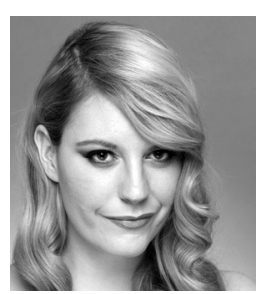

Lucía-Gloria Vázquez-Rodríguez has a MA degree in Film and Philosophy from King's College London, and is a PhD Candidate in Audiovisual Communication at the Complutense University of Madrid. She holds a scholarship to conduct research on queer cinema and TV and women filmmakers, areas in which she has published several articles and book chapters. She also collaborates in the coordination of the MA Degree in LGBTIQ+ Studies at the same university, and is a Member of the Gender, Aesthetics, and Audiovisual Culture Research Group.

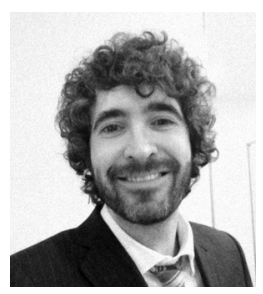

Francisco-José García-Ramos (PhD) is an Assistant Professor at the Department of Applied Communication Sciences at the Complutense University of Madrid. His current research focuses on LGBTIQ+ identities in film, television, advertising, and photography. He is a Researcher at the Complutense Research Group Gender, Aesthetics, and Audiovisual Culture and he is also a Member of the UNESCOUniTWIN Network of Gender, Media, and ICTs. He has published and coordinated numerous articles on gender and LGBTIQ+ issues within media and communication.

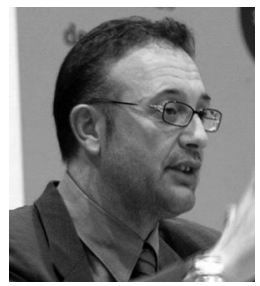

Francisco A. Zurian (PhD) is an Assistant Professor of Audiovisual Communication and Advertising at the Complutense University of Madrid, where he directs the Research Group Gender, Aesthetics, and Audiovisual Culture. He also coordinates the MA Degree in LGBTIQ+ Studies at the same university. His research focuses on aesthetics, film theory, audiovisual culture, gender and sexuality, feminism and women's studies, men studies and masculinities, and LGBTIQ+ studies. He is Author and Editor of several books, special issues, and articles focused on gender and sexuality within media. 